\title{
Identification of gliadin-binding peptides by phage display
}

Tingsu Chen ${ }^{1,4,5}$, Karolina Hoffmann², Sofia Östman ${ }^{3}$, Ann-Sofie Sandberg², Olof Olsson ${ }^{4^{*}}$

\begin{abstract}
Background: Coeliac disease (CD) is a common and complex disorder of the small intestine caused by intolerance to wheat gluten and related edible cereals like barley and rye. Peptides originating from incomplete gliadin digestion activate the lamina propria infiltrating $T$ cells to release proinflammatory cytokines, which in turn cause profound tissue remodelling of the small intestinal wall. There is no cure for CD except refraining from consuming gluten-containing products.

Results: Phage from a random oligomer display library were enriched by repeated pannings against immobilised gliadin proteins. Phage from the final panning round were plated, individual plaques picked, incubated with host bacteria, amplified to a population size of $10^{11}$ to $10^{12}$ and purified. DNA was isolated from 1000 purified phage populations and the region covering the 36 bp oligonucleotide insert from which the displayed peptides were translated, was sequenced. Altogether more than 150 different peptide-encoding sequences were identified, many of which were repeatedly isolated under various experimental conditions. Amplified phage populations, each expressing a single peptide, were tested first in pools and then one by one for their ability to inhibit binding of human anti-gliadin antibodies in ELISA assays. These experiments showed that several of the different peptideexpressing phage tested inhibited the interaction between gliadin and anti-gliadin antibodies. Finally, four different peptide-encoding sequences were selected for further analysis, and the corresponding 12-mer peptides were synthesised in vitro. By ELISA assays it was demonstrated that several of the peptides inhibited the interaction between gliadin molecules and serum anti-gliadin antibodies. Moreover, ELISA competition experiments as well as dot-blot and western blot revealed that the different peptides interacted with different molecular sites of gliadin.

Conclusions: We believe that several of the isolated and characterised gliadin-binding peptides described here could provide valuable tools for researchers in the field of CD by facilitating studies on localisation and uptake of various gliadin peptides in the small intestine. In future work, the potential of these peptides to detoxify gluten will be investigated.
\end{abstract}

\section{Background}

Coeliac disease (CD) is a common and complex inflammatory disorder of the small intestine that affects genetically susceptible individuals carrying HLA-DQ2 or -DQ8 haplotypes. Symptoms develop after ingestion of gluten storage proteins (prolamins) from wheat (gliadins), barley (hordeins), rye (secalins), and their crossbred varieties $[1,2]$. CD can be diagnosed at any age. It can either be asymptomatic or present with a broad spectrum of clinical manifestations. The classical

\footnotetext{
* Correspondence: olof.olsson@gu.se

${ }^{4}$ Department of Plant and Environmental Sciences, University of Gothenburg, SE-40530, Gothenburg, Sweden

Full list of author information is available at the end of the article
}

(typical) form of $\mathrm{CD}$ is usually characterized by gastrointestinal symptoms like flatulence, vomiting, constipation or persistent diarrhoea, general failure to thrive, mineral and vitamin deficiencies, and weight loss due to malabsorption. Atypical forms, on the other hand, present predominantly with extra-intestinal manifestations that include a blistering skin disease (Dermatitis herpetiformis), iron-deficiency anaemia, osteoporosis, fatigue and neurological complaints [3-6]. The prevalence of $C D$ is estimated to be about $1 \%$ in the Western populations $[7,8]$. Moreover, in recent years the total disease prevalence has increased. The reason for the observed raise is currently unknown and cannot be explained by the
C Biomed Central

(c) 2011 Chen et al; licensee BioMed Central Ltd. This is an Open Access article distributed under the terms of the Creative Commons Attribution License (http://creativecommons.org/licenses/by/2.0), which permits unrestricted use, distribution, and reproduction in any medium, provided the original work is properly cited. 
increase of $\mathrm{CD}$ diagnosis that occurred after introduction of antibody screening $[9,10]$.

In $\mathrm{CD}$ patients, peptides that originate from incomplete digestion of gluten prolamins, either in their native form or deamidated by tissue transglutaminase (tTG), bind to HLA-DQ2 or -DQ8 receptors of antigen presenting cells that activate the lamina propria infiltrating $\mathrm{CD}^{+} \mathrm{T}$ cells. As a response the $\mathrm{CD} 4^{+} \mathrm{T}$ cells release pro-inflammatory cytokines, in particular $\gamma$-interferon. Ultimately, this leads to profound tissue remodelling characterised by the atrophy of the small intestinal villi and hyperplasia of crypts [2,11-14]. Active CD is also characterised by high levels of antibodies against tTG and gliadin in the patients' sera. The role of anti-tTG IgA class antibodies is still unclear. However, it has been proposed that they may be involved in the development of mucosal damage [15]. Also IgG class antigliadin antibodies have been shown to contribute to the pathogenesis by activating the complement system or inducing antibody-mediated cytotoxicity [16].

$\mathrm{T}$ cell epitopes in wheat gluten proteins have been characterised within both gliadins and glutenins. A hierarchy exists within these epitopes. The majority of $C D$ patient-derived intestinal $\mathrm{T}$ cell clones recognise $\alpha$-gliadins, and less frequently $\gamma$-gliadins and glutenins [17-20]. The most prominent peptide is a 33-mer of $\alpha$ gliadins (residues 57-89) that contains six T-cell epitopes. Another fragments, also found in $\alpha$-gliadins (residues 31-43 and 44-55), seem to be important for the activation of the innate immunity system [18,21-23]. In a recent study gluten-specific $\mathrm{T}$ cells from peripheral blood of CD patients challenged either with wheat, barley, rye or a combination of the three cereals were used to identify the immunostimulatory sequences in these grains [24]. The $\alpha$-gliadin 33-mer was found immunogenic only after the wheat challenge while sequences from $\omega$-gliadin (wheat) and C-hordein (barley) were found to be immunodominant despite the grain consumed.

Currently there is no cure for $\mathrm{CD}$. The only existing therapy is a life-long adherence to a gluten-free (GF) diet [3]. However, several strategies that may in the future serve as alternatives to the GF diet have been proposed. $\mathrm{T}$ cell activation may be inhibited by molecules that block peptide binding to HLA-DQ2. Alternatively, inhibition of tissue transglutaminase may prevent gluten deamidation [25]. Supplementation with prolyl endopeptidases (PEPs), enzymes derived from moulds and bacterial strains, or with a mixture of PEP and cysteine endoprotease from germinating barley, which aid in digestion of immunostimulatory gluten peptides into harmless molecules, is under investigation [26-29]. Another possible therapeutic alternative that is currently pursued is a vaccine that contains a mixture of immunodominant peptides that trigger the immune response and are supposed to retrain the immune system of HLA-DQ2 positive CD subjects to tolerate gluten $[24,30]$. Furthermore, an inhibitor of paracellular permeability (AT-1001, larazotide acetate) has been shown to reduce the intestinal barrier dysfunction, production of pro-inflammatory cytokines, and GI symptoms in CD individuals after gluten exposure [31,32]. Moreover, attempts have been made to degrade toxic gluten sequences during sourdough fermentation with selected lactobacilli strains [33]. Finally, the potential of a linear polymeric binder P(HEMA-co-SS) to neutralise gliadin in vitro and in vivo in mice models have been described [34]. Another alternative could be blocking gliadin domains with synthetic peptides and thus preventing tTG modification and formation of immunostimulatory epitopes.

In the present study we have selected in vitro gliadinbinding peptides with the help of phage display. Phage display refers to a molecular method where gene libraries are constructed in filamentous bacteriophage in a way that each individual phage in the population will display a unique peptide or protein on its surface [35]. From such a population, phage that interact with in principle any a priori chosen molecule can be isolated and amplified. The concept has been used in many different variations to select and produce novel peptides that bind to target molecules of interest [36-38]. The aim of this work was to identify phage that express peptides specifically binding to different gliadin domains and to identify and characterise the gliadin-binding properties of the chosen individual peptides.

\section{Results}

\section{Purification and immobilisation of gliadin proteins}

Gliadin was semi-purified from commercially obtained gluten (Sigma) and from whole wheat grains as a comparison. Several proteins of varying molecular weights were obtained from both sources (Figure 1). Using a commercial gliadin ELISA kit it was confirmed that the included anti-gliadin antibodies reacted with the semipurified gliadin fractions. As a control, gliadin-like proteins (avenins) were extracted from oat grains but the commercial antibodies did not, as expected, react with the oat proteins (data not shown). The gliadin preparation was finally dissolved in either $0.1 \mathrm{M} \mathrm{NaHCO}_{3}$ or in $2 \mathrm{M}$ urea, added to microtiter plate wells and allowed to bind to plastic. After washing, bound gliadin molecules were quantified with an ELISA assay using the commercial human anti-gliadin IgG antibodies. This confirmed that gliadins indeed had been immobilised to the wells and that the antibodies used recognised both the gliadin $\mathrm{NaHCO}_{3}$ - and urea-treated molecules. However, the detection limit was reduced about 5 times when gliadins 


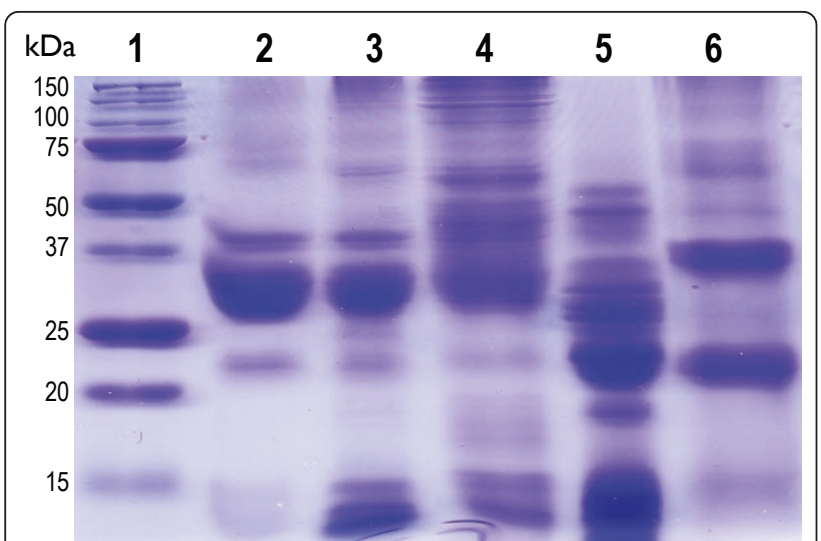

Figure 1 SDS-PAGE separation of gliadin and gliadin-like proteins. Lane 1: molecular weight standard; lane 2: gliadin purified from gluten (Sigma) in 40\% ethanol; lane 3: gliadin purified from Triticum aestivum cv. Surco in 40\% ethanol; lane 4: gliadin purified from Triticum aestivum cv. Surco in $2 \mathrm{M}$ urea; lane 5: gliadin-like (avenins) proteins purified from Avena sativa cv. Leon in 40\% ethanol; lane 6: avenins purified from Avena sativa cv. Leon in $2 \mathrm{M}$ urea.

were dissolved in urea indicating that the 3D structure of the antibody-binding sites of gliadin were affected by the buffer used (Figure 2).

\section{Selection of peptides specifically binding to gliadin peptides by biopanning}

Two different phage display libraries, one displaying 12mer and one displaying 7-mer random peptides, were panned to the immobilised gliadin. In each panning round unbound phage were removed by washing. Remaining bound phage were eluted and allowed to infect $E$. coli cells. After single plaque amplification and phage purification a new round of panning was performed with the obtained phage population. Panning was done both with gliadin dissolved in urea and in

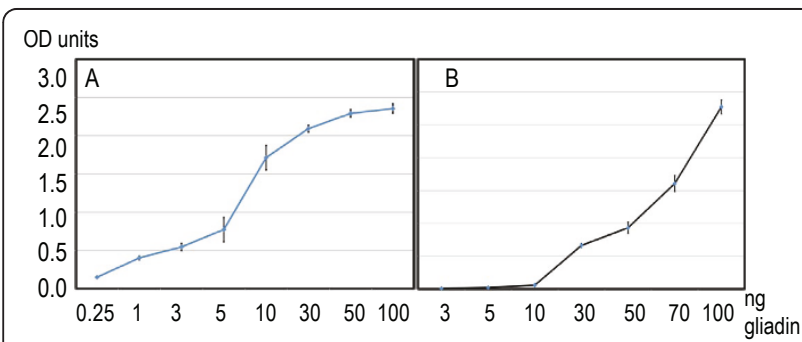

Figure 2 Quantification of immobilised semi-purified gliadin (Sigma). Microtiter wells were coated with increasing amounts of gliadin (ng) as indicated on X-axis. Commercial anti-gliadin antibodies bound to the coated gliadin were quantified by adding a secondary AP-tagged goat anti-human IgG antibody and measured as absorbance at $405 \mathrm{~nm}$ (Y-axis).A. Gliadin dissolved in $100 \mu \mathrm{l} 0.1 \mathrm{M} \mathrm{NaHCO}_{3}$ (pH 8.6).B. Gliadin dissolved in $100 \mu \mathrm{l} 2 \mathrm{M}$ urea.Error bars indicate variation between two different experiments.
$\mathrm{NaHCO}_{3}$. Since electrostatic binding of the phage to the target protein weakens with increasing ionic strength, which in turn influences the specificity of the interaction [39], different buffers with different ionic strengths were tested prior the actual panning experiments. After optimising parameters like binding, washing, and elution conditions, a protocol was developed in which the phage recovery increased after each round of panning. Typically five rounds of panning were done. After the final plating, 100 plaques were randomly picked and amplified separately. Phage DNA was then isolated from each isolate, the oligonucleotide inserts sequenced and the deduced amino acid sequence of the displayed peptide determined.

In total, inserted individual oligomer sequences from approximately 1000 phage, selected under a number of different panning conditions, were obtained. Although identical sequences were frequently picked up in independent experiments, altogether more than 160 unique sequences encoding peptides with potential gliadin binding activities were identified (data not shown). All obtained sequences originated from the 12-mer library. Many of the peptides could be crudely divided into subgroups based on sequence similarities. However, more than a half of the peptides showed no obvious sequence similarities to each other. This indicates that the peptide-targeted surfaces in the used gliadin preparations are much diversified.

As a control, panning against microtiter plates coated with BSA was performed. Peptides identified in this way were denoted control peptides (CP). Altogether, five different $\mathrm{CP}$ sequences were identified. There were no sequence similarities between these control sequences and any of the gliadin binding sequences.

\section{Rescuing selected phage clones}

In order to confirm that the selected phage clones interacted with gliadin proteins, nine different phage populations that had repeatedly been picked up in different panning experiments were chosen. Together, these nine sequences represent $89 \%$ of all identified gliadin-binding sequences (Table 1 ). The remaining approximately 150 sequences thus were found in only $11 \%$ of the cases. From each of the nine populations $1 \times 10^{11}$ pfu were incubated with the gliadin-coated microtiter wells. In addition, a phage population representing a non gliadinbinding control sequence (CP31) was incubated with the gliadin-coated microtiter wells. After extensive washing, remaining phage were eluted and counted. This showed that phage carrying the CP31 control peptide were very poor binders, as only $1 \times 10^{4} \mathrm{pfu}$ were rescued from this population under the conditions used. From the phage that carry specific peptides, on the other hand more than $1 \times 10^{8}$ pfu were rescued (Figure 3 ). Phage 
Table 1 Most frequently identified phages and peptides in this study

\begin{tabular}{|c|c|c|}
\hline Peptide & Sequence & Frequency (\%) \\
\hline P61 & W H W R N P F W Y L K & 22.5 \\
\hline P64 & WHWTWLSEYPPP & 21.5 \\
\hline P22 & LETSKLPPPAFL & 12.5 \\
\hline P62 & WHWS Q WLSGSPP & 8.5 \\
\hline P63 & W H R T P Q F W A F P W & 7 \\
\hline P21 & SVSVGMKPSPRP & 5 \\
\hline P66 & WHKTPWFWPTNL & 5 \\
\hline P67 & W HW SW Q P Q R H S P & 4 \\
\hline P65 & W HW Q Y T PWWRGS & 3 \\
\hline Sum & & 89 \\
\hline CP31 (control) & A Y Y P Q NHKSNAE & NA \\
\hline
\end{tabular}

P61, which was the was most frequently picked up in the panning experiments, displayed the highest relative binding affinity, while phage carrying peptides P21, P22, P62, P64, P65 and P67 showed intermediate affinities (Figure 3).

\section{Selected phage clones hinder anti-gliadin antibody binding to gliadin}

To investigate if the selected, gliadin-interacting phage could hinder antibody binding to gliadin, $1 \times 10^{11} \mathrm{pfu}$ of the same nine phage populations as in the previous experiment (Figure 3) were added to wells coated with $10 \mathrm{ng}$ gliadin. The CP31 phage population as well as a buffer solution without phage were used as controls. To investigate if the peptides not only interfered with commercial anti-gliadin antibody binding but also interfered with the interaction between gliadin and antibodies present in

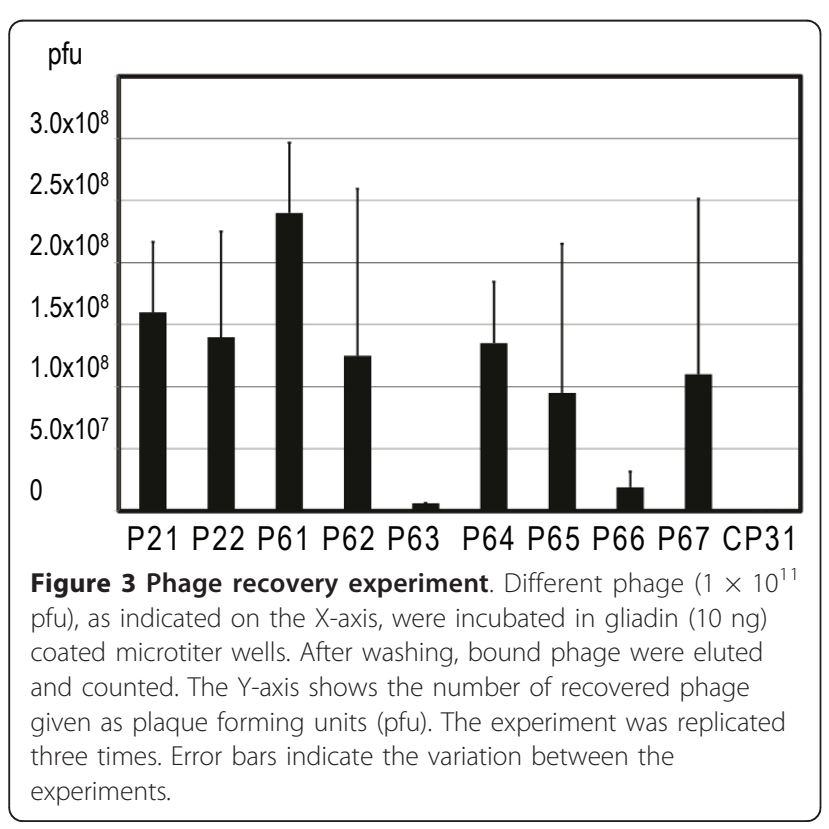

serum from individuals with suspected CD, after extensive washing, pooled sera from 20 individuals was added. Again, the amount of bound antibody was quantified by adding an AP-labelled secondary anti-human IgG antibody. This showed that the greatest signals i.e. most antibodies bound were from the controls where no gliadinblocking peptides were present (Figure 4). On the other hand, all the selected phage populations blocked the signal to various extents, indicating that the peptides displayed on the phage interfered with the anti-gliadin antibody-gliadin interaction. Wells incubated with phage populations P61 and P64 gave the lowest signal indicating, in agreement with the previous experiment (Figure 3), that these were the most efficient gliadin binders.

\section{Gliadin binding of synthetic peptides}

Since all selections were based on phage-displayed peptides, we investigated whether synthetic peptides, with the same sequence as those in the selected phage, maintained the gliadin-binding ability also when removed from the steric context of the phage surface. Peptides based on the most frequently identified sequences, P64, P61 and P22 (Table 1) as well as the non-specifically binding control peptide CP31, were synthesised. A biotin label was added at the $\mathrm{N}$-terminus of all the peptides to facilitate detection. To test peptide-gliadin binding, different concentrations of gliadin proteins (110 ng) were immobilised in microtiter wells and $10^{15}$ molecules (1.67 nmoles) of the synthetic peptides were added to the wells. After incubation and extensive washing to remove unbound peptides the biotin signals from the remaining peptides were quantified. The results showed

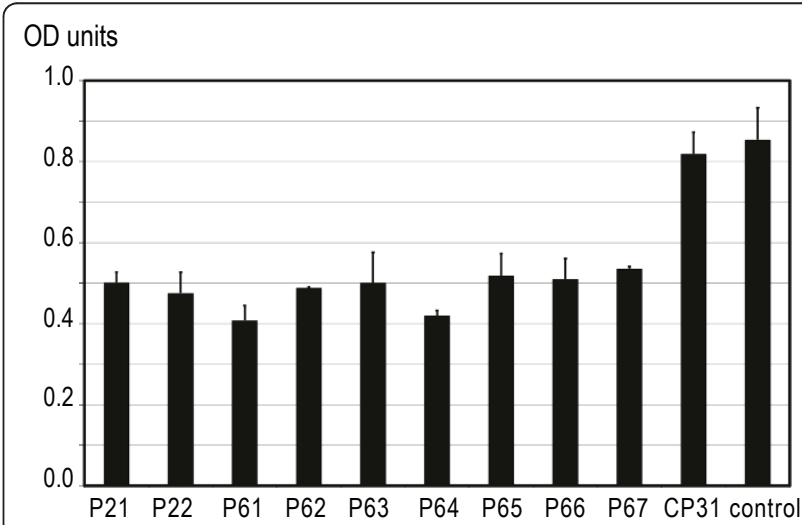

Figure 4 Gliadin-anti-gliadin antibody interaction in the presence of peptide-displaying phage. The $Y$-axis shows different phage displaying peptides tested. Phage $\left(10^{11} \mathrm{pfu} / \mathrm{ml}\right)$ were added to microtiter wells coated with $10 \mathrm{ng}$ gliadin. After incubation and extensive washing, pooled sera from patients with suspected CD were added. The amount of bound antibody was determined by adding a secondary AP-tagged goat anti-human IgG antibody, and measured as absorbance at $405 \mathrm{~nm}$ (Y-axis). 
that P61 had the highest binding activity, P64 somewhat weaker, and P22 the weakest binding activity (Figure 5), corroborating the experiments with the phage carrying peptides (Figure 3 and 4). No activity at all could be detected from the incubations with the control peptide. As expected, the number of bound peptides increased with increasing gliadin concentrations (Figure 5).

\section{Gliadin-blocking activity of selected synthetic peptides}

To confirm that the free peptides could block anti-gliadin antibody-gliadin interactions with similar efficiency as the phage-displayed peptide, 1.67 nmoles $\left(10^{15}\right.$ molecules) of the synthetic peptides were mixed with increasing concentrations of gliadin (0.25-100 ng), followed by an incubation of the peptide/gliadin mixture in anti-gliadin antibody coated wells. After incubation and washing away unbound gliadin and peptides, a secondary antibody binding to the solid phase antibody-antigen complex was added, and the amount of complex quantified by means of the tag on the secondary antibody. This showed that the P64 and P61 peptides interfered with or blocked antigenic sites on the gliadin molecules, since fewer signals were obtained with these peptides than with P22, CP31 and the no peptide control (Figure 6). Furthermore, the blocking effect was visible in the whole concentration range (0.5-100 ng) of gliadin tested (Figure 6).

To further test the binding efficiencies of the peptides, two best peptides P61 and P64 and the control peptide CP31 were diluted in several steps and incubated with 1 ng of gliadin followed the incubation in the antibodycoated microtiter wells. This showed that as little as $10^{9}$ peptide molecules ( 0.167 pmoles) could interfere with

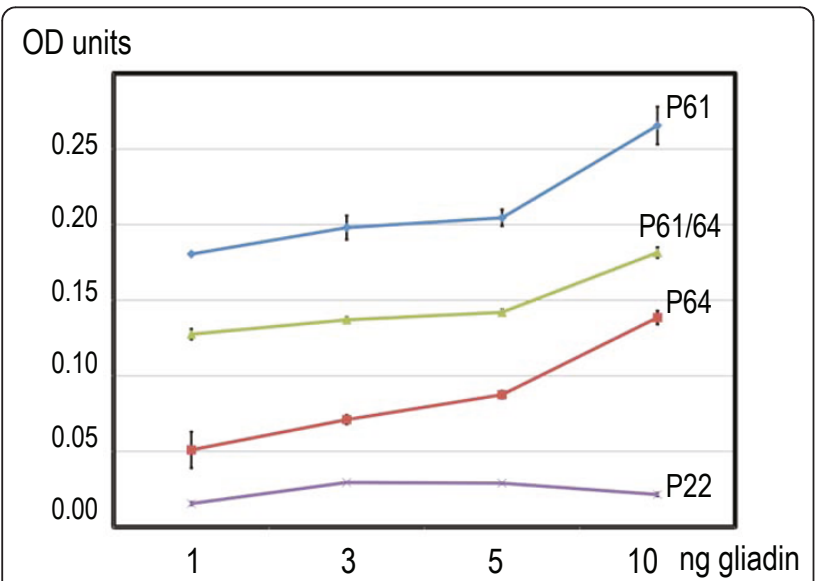

Figure 5 Binding of synthetic peptides to gliadin proteins. Microtiter wells were coated with increasing amounts of gliadin (ng) as indicated on the X-axis. Afterwards $10^{15}$ molecules (1.67 nmoles) of biotinylated peptides, P61, P64, or P22 were added to the wells. Bound peptides were quantified as absorbance units at $405 \mathrm{~nm}$ (OD units) by means of the biotin adduct as described in Methods. P61/64 is a 1:1 mixture of peptides P61 and P64.

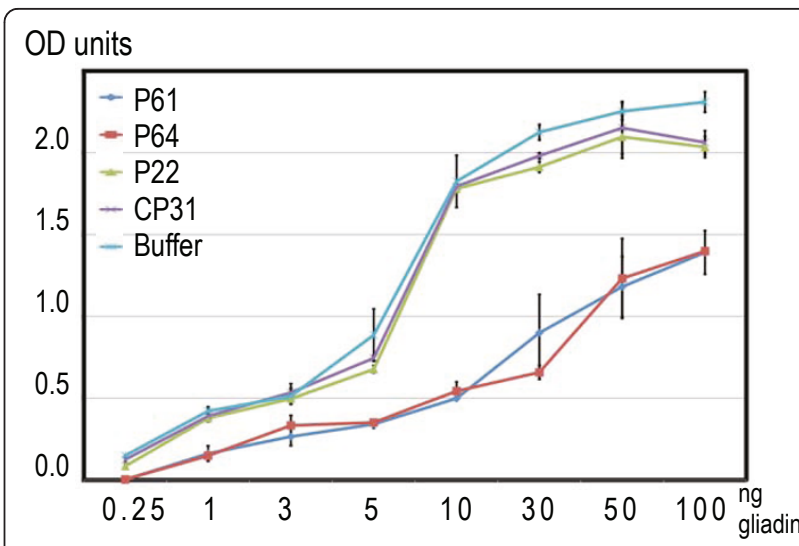

Figure 6 Inhibition of gliadin/anti-gliadin antibody binding by selected synthetic peptides. Increasing amounts of gliadin in ng (as indicated on the $\mathrm{X}$-axis) were incubated with 1.67 nmoles of biotin-labelled synthetic peptides ( $10^{15}$ molecules) for $1 \mathrm{~h}$ at room temperature. Buffer $\left(0.1 \mathrm{M} \mathrm{NaHCO}_{3}\right)$ without peptides was used as a control. The mixes were then added to anti-gliadin monoclonal antibody-coated wells provided with the Immunotech gliadin ELISA kit. After incubation for $1 \mathrm{~h}$ at room temperature, gliadin-antibody complexes immobilised in the wells were quantified as described (see Methods) and given as absorbance units at $450 \mathrm{~nm}$ (Y-axis). Error bars show the variation in three different experiments.

the anti-gliadin antibody-gliadin interactions to a level detectable in the experiment (Figure 7).

\section{Dot blot and western blot analysis}

To further verify the physical interaction of the peptides and gliadin, and to elucidate if the peptides preferentially bind to specific proteins in the semi-purified gliadin

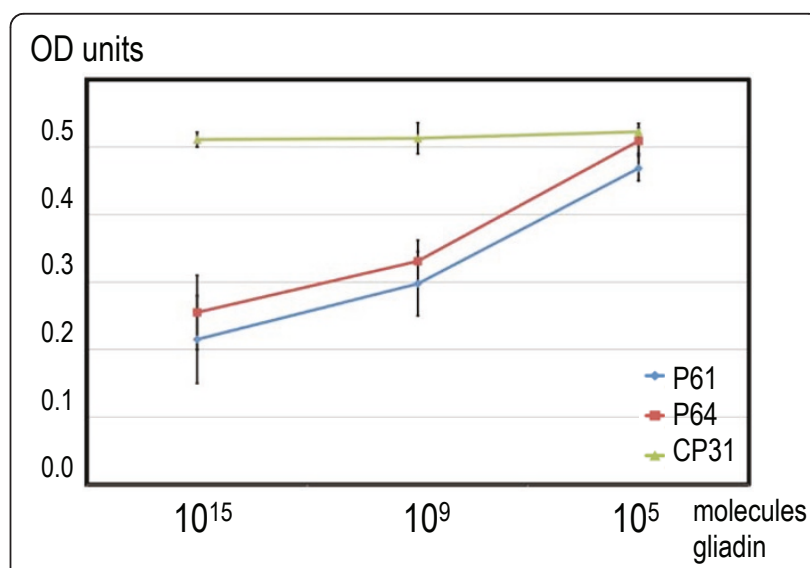

Figure 7 Concentration dependency of peptide gliadin/antigliadin antibody binding inhibition. Gliadin was diluted to $1 \mathrm{ng} /$ $\mathrm{ml}$ and mixed with 1.67 nmoles, 0.167 pmoles, and 0.0167 fmoles $\left(10^{15}, 10^{9}\right.$, and $10^{5}$ molecules respectively) of peptides P61, P64, and CP31. Afterwards the gliadin/peptides mixes were added to antigliadin, monoclonal antibody-coated wells and incubated for $1 \mathrm{~h}$. The formed gliadin/antibody complexes immobilised in the wells were quantified as described (see Methods) and given as absorbance units at $450 \mathrm{~nm}$ (Y-axis). 
fraction used here, dot blot and western blot experiments were performed. In the dot blot experiments, increasing concentrations $(25 \mathrm{ng} / \mu \mathrm{g})$ of the gliadin preparation were spotted on filters. The filters were then incubated with either of the P22, P61, P64 or CP31 peptides, and subsequently washed. Bound peptides were quantified with an anti-biotin AP-labelled antibody recognising the biotin tag on the peptides. The results from these analyses again confirmed that the peptides physically interacted with gliadin and as previously, the P61 peptide had the highest binding activity, followed by the P64 peptide. No binding could be detected with the P22 and the CP31 peptides (Figure 8).

In the western blot experiments, gliadin proteins were separated on SDS-PAGE gels and blotted to nitrocellulose membranes. By using the P61, P64, P22 or CP31 peptides as probes and again detecting peptides bound to the filter by means of the secondary AP-labelled antibiotin antibody it became clear that, as in the dot blot experiments, P61 and P64 showed the strongest binding (Figure 9). Both these peptides interacted with proteins in the 29-30 kDa range, and in addition P61 also bound to proteins between $49-70 \mathrm{kDa}$. Thus, the two peptides have overlapping but distinct binding specificities. A similar pattern was obtained both when analysing the gliadin extracted from Sigma gluten and gliadin extracted from wheat (Figure 9).

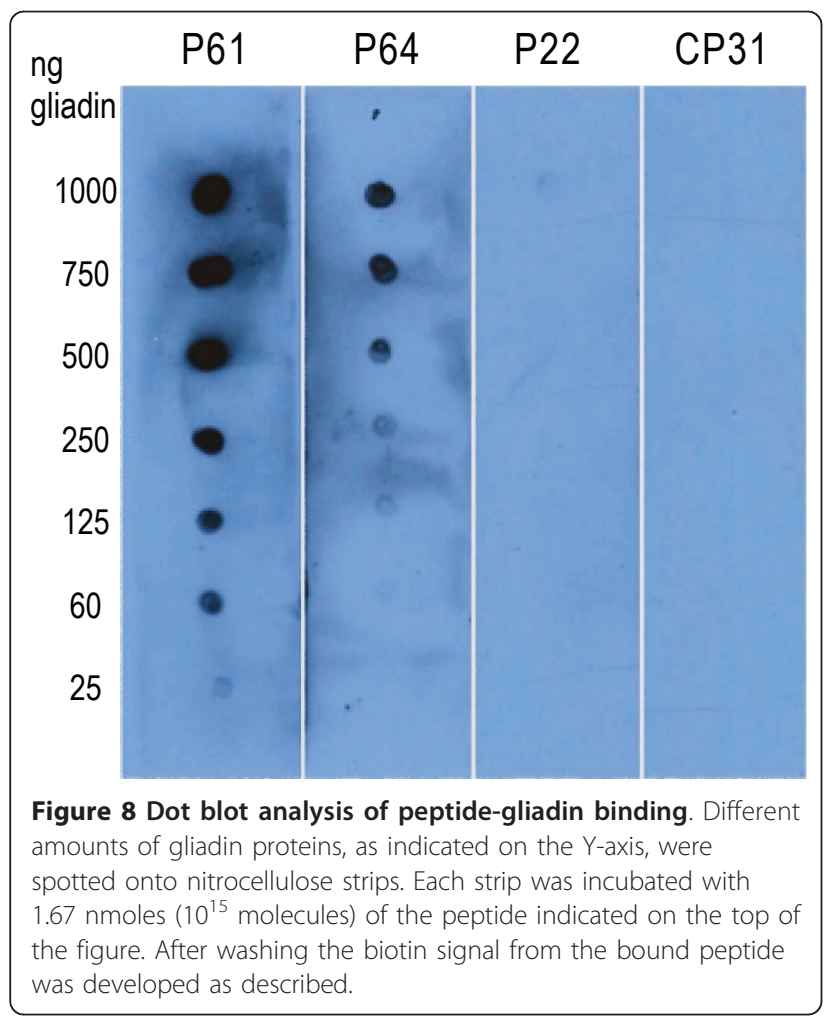

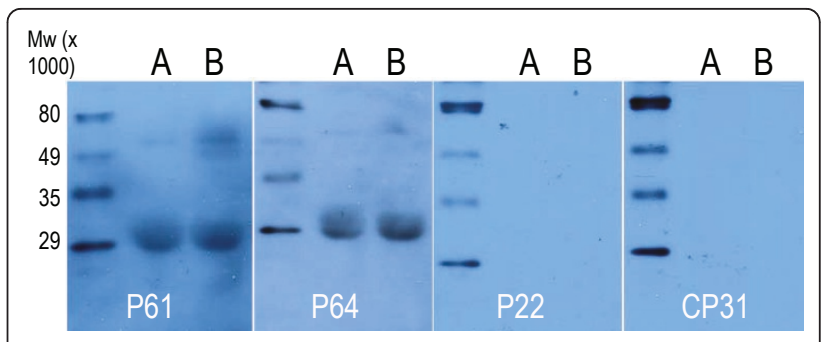

Figure 9 Western blot analysis of peptide-gliadin binding. 10 $\mu \mathrm{g}$ of gliadin extracted from Sigma gluten (A) or $10 \mu \mathrm{g}$ of gliadin extracted from Surco wheat (B) was loaded on a polyacrylamide gel. Separated proteins were transferred to a nitrocellulose membrane. Each membrane was incubated with 1.67 nmoles ( $10^{15}$ molecules) of the peptide indicated at the bottom of the figure. After washing the biotin signal from the bound peptide was developed as described.

\section{Discussion}

Wheat gluten consists of a complex mixture of proteins that based on their common structures can be divided into three groups: a high molecular weight (HMW) group that contains $\mathrm{HMW}$-glutenin subunits with $\mathrm{Mr}$ $\sim 67-88 \mathrm{kDa}$; a medium molecular weight (MMW) group containing $\omega$-gliadin proteins with $\mathrm{Mr} \sim 34-55$ $\mathrm{kDa}$; and a low molecular weight (LMW) group with $\alpha$ / $\beta$-, $\gamma$-gliadins and LMW-glutenin subunits with $\mathrm{Mr} \sim 28-$ $39 \mathrm{kDa}$ [40-43]. Several of the glutenin and gliadin proteins contain repeated proline and glutamine residues, especially QQPFP and PQQPF motifs, which are resistant to complete digestion by gastric and pancreatic enzymes [18]. The repeats can trigger immune response and appear to be especially important for the specific gluten peptide recognition by $\mathrm{CD}^{+} \mathrm{T}$ cells $[17,44]$. Previously, it was shown that phage display might be a useful technology to identify peptides that bind to gliadin residues, although no sequences were shown [38]. Here, we extended this work to include several different gliadin proteins to increase the probability of identifying phage that bound to reactive surfaces (Figure 1). Glutamine residues within gliadin can be deamidated by tissue transglutaminase (tTG), which will further enhance the pathologic immune response [45]. If blocking peptides efficiently inhibit recognition of gliadin by tTG they will most probably aid in limiting the development of $\mathrm{T}$ cell epitopes. In a recently published study we have shown that when in complexes with the selected blocking peptides, the in vitro enzymatic modification of gliadin by tTG was reduced by one-third [46].

There is no cure for CD. The only available therapy is a life-long exclusion of gluten from a diet. The variety of bakery and pastry gluten-free products is limited and the price is higher than their gluten containing equivalents [47]. Moreover, these products often do not meet the dietary requirements, as they tend to be high in fat and 
low in fibre as compared to gluten-containing equivalents $[47,48]$. Furthermore, naturally gluten-free grains and flours can be contaminated with gluten during fieldwork, transport, processing or in a store if grains are kept in open containers $[49,50]$. One alternative strategy would be to neutralise minor contaminations in e.g. oat, rice or maize products by mixing in molecules that block or digest the harmful motifs in gluten molecules [25]. Gluten-blocking peptides, like the ones described in this work, could perhaps be one way to detoxify disease-inducing gluten peptides in the future.

By using a number of different panning conditions and gliadin proteins dissolved in either urea or $\mathrm{NaHCO}_{3}$ a large number of phage displaying different peptide sequences has been identified. To investigate if the identified peptides could interfere with the human anti-gliadin antibody and gliadin interaction, we mixed peptidecarrying phage with gliadin and pooled sera originating from patients with suspected CD. In that way we demonstrated that the phage indeed inhibited interactions between gliadin and human anti-gliadin antibody (Figure 4). For these analyses we used patient sera from a biobank. The sera were selected for having high titers of anti-gliadin antibodies $(\leq 100 \mathrm{U} / \mathrm{ml})$ and positive or high titers of anti-transglutaminase IgA antibodies, although we had no specific information regarding the patients' clinical diagnosis. The production of anti-gliadin antibodies is not specific to coeliac disease since slightly elevated serum concentrations are also found in other gastrointestinal disorders and even in normal individuals [51,52]. However, the levels of anti-gliadin antibodies in patients without coeliac disease seem to be much lower compared to our selected serum samples [53]. As our patients had high levels of both anti-gliadin and anti-transglutaminase antibodies it is likely that they had CD.

To verify whether the peptides, also when removed from the context of the phage, could interact with gliadin, we synthesised three peptides that were repeatedly identified in independent panning experiments and one control peptide that only interacted with BSA. We could then show that two of the peptides, P61 and P64 indeed interfered with the gliadin anti-gliadin antibody binding (Figure 6 and 7). In this case, two different monoclonal anti-gliadin antibodies provided by a commercial kit were used. In addition, by means of the biotin label attached to the peptides, we also showed in western blot experiments that P61 and P64 could bind to several of the separated and immobilised gliadin proteins (Figure 9).

Since we have so far only studied the nine gliadinbinding peptides that were most often picked up, we still have more than 150 additional peptides to test. Most likely, several of these peptides will also bind to gliadin. Since all individual peptides will bind to different sites on the gliadin complex, pooling of several different peptides could generate synergistic effects, and it should be possible to develop this concept in the direction of a drug against CD. However, many more experiments have to be performed, addressing issues like the stability of the peptide-gliadin interaction in chemical conditions likely to be encountered in the gut or in food preparation, the characterization of the actual binding sites in more detail, and the interaction with digestive enzymes and tissue transglutaminase etc. before any conclusions about the usefulness of these peptides in a therapeutic situation can be drawn.

\section{Conclusions}

Finally, there are still several unanswered questions on the role of gliadin in the development of CD. Some of the gliadin-binding peptides presented here, labelled in different ways, could provide valuable tools for researchers in the field of CD to study localisation and uptake of various gliadin peptides in the small intestine.

\section{Methods}

\section{Gliadin preparation}

Gliadin was extracted from gluten (Sigma Aldrich, Stockholm, Sweden) as described [41] with some modifications. Essentially, 1.5 g gluten was dissolved in $20 \mathrm{ml} 25 \mathrm{mM}$ $\mathrm{Na}_{2} \mathrm{SO}_{3}$, vortexed $15 \mathrm{~min}$ at room temperature (RT) and centrifuged at $5000 \mathrm{~g}$ for $5 \mathrm{~min}$. The pellet was washed in $20 \mathrm{ml} 25 \mathrm{mM} \mathrm{Na}_{2} \mathrm{SO}_{3}$ and suspended in $70 \%$ ethanol by incubating at $70^{\circ} \mathrm{C}$ for $30 \mathrm{~min}$ with vortexing every $5 \mathrm{~min}$. Undissolved material was eliminated by centrifugation, and the supernatant was incubated on ice for $2 \mathrm{~h}$ to precipitate the high molecular weight glutenin, which was eliminated by centrifugation for $10 \mathrm{~min}$ at $4^{\circ} \mathrm{C}$. Subsequently the supernatant was mixed with $6 \mathrm{M} \mathrm{NaCl}$ in $70 \%$ ethanol to a final concentration of $256.67 \mathrm{mM} \mathrm{NaCl}$ and centrifuged for $10 \mathrm{~min}$ at $4^{\circ} \mathrm{C}$. The supernatant that contained the gliadin-LMW-glutenin enriched fraction (in $70 \%$ ethanol and $256.67 \mathrm{mM} \mathrm{NaCl}$ ) was stored at $-80^{\circ} \mathrm{C}$ until further use. In addition, seeds ( $c$ a $1 \mathrm{~g}$ ) from Surco (wheat) and Leon (oat) varieties were ground and dissolved in $1 \mathrm{ml}$ of $40 \%$ ethanol. The samples were centrifuged at $5000 \mathrm{~g}$ for $10 \mathrm{~min}$ and the supernatant stored at $-20^{\circ} \mathrm{C}$.

\section{Immobilisation of gliadin proteins}

Gliadin (1-100 ng) prepared as above and diluted in 0.1 $\mathrm{M} \mathrm{NaHCO}_{3}(\mathrm{pH}$ 8.6) was incubated in 96-well microtiter (EIA/RIA) plates (Corning Inc. Corning, NY) at $4^{\circ} \mathrm{C}$ for $16 \mathrm{~h}$. The amount of immobilized gliadin was quantified using the Anti-Gliadin IgG Kit (Biohit Oyi, Helsinki, Finland) according to the producer's protocol where the "positive control" patient serum provided in the kit was used as the primary anti-gliadin antibody, and labelled 
polyclonal anti-human IgG (goat) antibody was used as the secondary antibody. The positive signal was developed using the p-nitrophenyl phosphate solution (NPP) reagent and measured as absorbance at $405 \mathrm{~nm}$.

\section{In vitro panning of phage display peptide library}

The Ph.D. $-12^{\text {TM }}$ Phage Display Peptide Library kit, including E. coli ER 2738 host strain, was purchased from New England BioLabs (Beverly, MA). Selection of peptides was carried out according to the manufacturer's instructions. $25 \mu \mathrm{g}$ of gliadin in $0.1 \mathrm{M}$ sodium bicarbonate ( $\mathrm{pH} 8.6$ ) was coated onto 96-well microtiter plates (EIA plates) at $4^{\circ} \mathrm{C}$ overnight. Remaining surfaces in the wells were then blocked for $2 \mathrm{~h}$ at $4^{\circ} \mathrm{C}$ with $5 \% \mathrm{BSA}$ diluted in $0.1 \mathrm{M}$ sodium bicarbonate $(\mathrm{pH} 8.6)$ with $0.02 \% \mathrm{NaN}_{3}$. Afterwards, approximately $1 \times 10^{11}$ plaque forming units (pfu) of phage were diluted in $100 \mu \mathrm{l}$ of 1 $\times$ LIB (Low Ionic Strength buffer, $10 \mathrm{mM}$ sodium phosphate, $\mathrm{pH} 6.0$ ) with $0.5 \%$ BSA and $0.1 \%$ Tween-20, and incubated with gliadin for $1 \mathrm{~h}$ at RT with gentle shaking. The same procedure was used in negative control pannings but in this case the wells were just coated with BSA (no gliadin present). After phage incubation, the wells were washed ten times with LIB with $0.5 \%$ Tween20. Unbound phage were discarded. Bound phage were eluted with $0.2 \mathrm{M}$ glycine- $\mathrm{HCl}, 1 \% \mathrm{BSA}$ (pH 2.2) and amplified by infecting E. coli ER2738 host cells. After $4.5 \mathrm{~h}$ of growth at $37^{\circ} \mathrm{C}$ phage were removed from bacterial cells by centrifugation. The phage present in the supernatant were precipitated by adding $1 / 6$ volume of PEG/NaCl solution (20\% w/v polyethylene glycol-8000; $2.5 \mathrm{M} \mathrm{NaCl}$ ), and incubated for $16 \mathrm{~h}$ at $4^{\circ} \mathrm{C}$. The precipitate was resuspended in a small volume of LIB, and amplified elutes were titrated to determine phage concentration. Typically, the panning procedure was repeated five times after which phage were plated and random plaques were picked. After amplification, phage were purified by precipitation in $\mathrm{PEG} / \mathrm{NaCl}$ followed by resuspension in $1 / 50$ volume of the original volume in 1 $\times$ LIB with $0.02 \% \mathrm{NaN}_{3}$ and stored in aliquots at $4{ }^{\circ} \mathrm{C}$. These phage were then used in the binding specificity and affinity experiments and for DNA extraction.

\section{DNA sequencing}

Single-stranded phage DNA was isolated by incubation in iodide buffer (4 M NaI, $1 \mathrm{mM}$ EDTA in $10 \mathrm{mM}$ Tris$\mathrm{HCl}, \mathrm{pH} 8.0$ ) to denature the phage coat protein. Released DNA was then precipitated in 70\% ethanol. Purified DNA was sequenced by Microgen Inc. (Seoul, Korea) and MWG Biotech AG (Martinsried, Germany).

\section{Phage recovery experiment}

Coated and blocked (as described above) microtiter plate wells were washed three times with $0.1 \%$ LIBT
(LIB buffer with $0.1 \%$ Tween-20). Selected phage were serially diluted in $0.1 \%$ LIBT buffer and $100 \mu \mathrm{l}$ was added to the wells. After addition of 1\% BSA the wells were incubated for $1 \mathrm{~h}$ at $37^{\circ} \mathrm{C}$. Control wells were incubated in the same buffer but without phage. Next, the wells were washed six times with $0.5 \%$ LIBT to remove the unbound phage. The remaining phage were eluted with glycine- $\mathrm{HCl}(\mathrm{pH} 2.2)$ in $1 \% \mathrm{BSA}$ and phage titers were determined.

\section{Patient antisera}

The serum samples were obtained from a biobank at the immunological laboratory, Sahlgrenska University hospital, Gothenburg, Sweden. The samples were selected for high titers $(\leq 100 \mathrm{U} / \mathrm{ml})$ of anti-gliadin IgA antibodies and for positive or high titers of anti-transglutaminase IgA antibodies. The serum samples were prepared according to standard procedure, i.e. blood was drawn into unprepped tubes and serum was collected by centrifugation at $3000 \mathrm{~g}$. Serum was diluted (1:500) with dilute buffer (same as dilute buffer from Anti-Gliadin IgG kit). The serum used here was a pool from 20 different anonymous patients.

\section{Phage ELISA}

Since the phage display was done on a mixture of different gliadin proteins, potentially a lot of different peptides could bind to the coated proteins. To block out as many peptides as possible in the same experiment pooled polyclonal patient sera isolated from 20 different patients with suspected CD were used.

Microtiter plate wells were coated with $100 \mu \mathrm{l}$ of gliadin proteins $(0-100 \mu \mathrm{g} / \mathrm{ml})$ dissolved in $0.1 \mathrm{M}$ $\mathrm{NaHCO}_{3}(\mathrm{pH} 8.6)$ and incubated overnight at $4{ }^{\circ} \mathrm{C}$. Subsequently, the wells were blocked with $200 \mu \mathrm{l}$ of blocking buffer (5\% BSA in $0.1 \mathrm{M} \mathrm{NaHCO}_{3}, \mathrm{pH} 8.6$; with $0.02 \% \mathrm{NaN}_{3}$ ) for $2 \mathrm{~h}$ at $4^{\circ} \mathrm{C}$ and washed three times with $0.1 \%$ LIBT (LIB with $0.1 \%$ Tween-20). Phage $\left(1 \times 10^{11}\right)$ carrying different peptide sequences in $100 \mu \mathrm{l}$ blocking buffer were transferred to the coated wells and incubated at $37^{\circ} \mathrm{C}$ for $1 \mathrm{~h}$. Unbound phage were removed by washing six times with $0.5 \%$ LIBT $(1 \times$ LIB buffer with $0.5 \%$ Tween-20). After this, $100 \mu$ pooled patient antiserum (diluted 1:500 with dilution buffer from the Anti-Gliadin IgG kit, Biohit Oyi, Helsinki, Finland) was added. After the $30 \mathrm{~min}$ incubation at RT the wells were washed four times with $1 \times$ ELISA washing buffer (Phosphate Buffered Saline, pH 7.2, 0.05\% Tween-20, Biolegend, San Diego, CA). For detection, $100 \mu \mathrm{l}$ of AP-linked, goat antihuman IgG (Invitro/Biolabs, Beverly, MA) diluted $(1: 4500)$ with dilution buffer from the Anti-Gliadin IgG kit was added to the wells and incubated for 30 min at RT. After washing four times with $1 \times$ ELISA 
washing buffer, $100 \mu \mathrm{l}$ of Nitrophenyl Phosphate Disodium substrate solution (NPP) (Invitrogen, Madison, WI) was added and incubated for $30 \mathrm{~min}$ at RT. Finally, the signal was detected by measuring absorbance at $405 \mathrm{~nm}$ in a microplate reader.

\section{Peptide synthesis}

Four peptides, denoted P61, P64, P22 and CP31 were synthesized at $>95 \%$ purity by Bio-Synthesis Inc. (Lewisville, TX), with biotin added to the $\mathrm{N}$ terminus. Peptides were dissolved in $150 \mu \mathrm{l}$ DMF (dimethylformamide) and diluted to $1 \mathrm{ml}$ with $0.05 \mathrm{M}$ phosphate buffer containing $0.15 \mathrm{M} \mathrm{NaCl}, \mathrm{pH} 7.4$ (Peptide Dilution Buffer, PDB) to a final concentration of $16.7 \mu \mathrm{M}$. Aliquots were stored at $-20^{\circ} \mathrm{C}$ until further use.

\section{Binding of synthetic peptides to gliadin proteins} $100 \mu \mathrm{l}$, corresponding to $1.67 \mathrm{nmoles}\left(10^{15}\right.$ molecules) of the synthesized peptides were added to gliadin-coated microtiter wells (1-100 $\mathrm{ng}$ ) and was incubated in $0.1 \mathrm{M}$ $\mathrm{NaHCO}_{3}(\mathrm{pH} 8.6)$ for $1 \mathrm{~h}$ at $37 \mathrm{C}$.

The wells were washed four times with $1 \times$ ELISA buffer (diluted from 20 x ELISA washing buffer, Biolegend, San Diego, CA) after which $100 \mu \mathrm{l}$ anti-biotin APlinked antibody (http://www.cellsignal.com) diluted 1:3000 was added. After the 30 min incubation at RT, and washing (four times) with $1 \times$ ELISA buffer, $200 \mu \mathrm{l}$ of $1 \times$ NPP substrate (Invitrogen, Carlsbad, CA) was added to the wells. After the $30 \mathrm{~min}$ incubation at RT in the dark $100 \mu \mathrm{l}$ of stop solution was added, the plates were shaken, and the signal was read at $405 \mathrm{~nm}$.

\section{Inhibition of gliadin-anti-gliadin antibody binding by selected synthetic peptides}

Gliadin was prepared as described and diluted to a final concentration of $100,50,30,10,5,3,1$ and $0.5 \mathrm{ng} / \mathrm{ml}$ in $200 \mu \mathrm{l}$ dilution buffer provided in the Immunotech ELISA kit (Radiová 1, Prague, Czech Republic). Each gliadin dilution was incubated with 1.67 nmoles $\left(10^{15}\right.$ molecules) of the synthetic peptides P64, P61, P22, CP31 and a control with only $0.1 \mathrm{M} \mathrm{NaHCO}_{3}$ buffer at $\mathrm{RT}$ for $1 \mathrm{~h}$. The gliadin/peptide mixtures were then added to microtiter wells coated with two different antigliadin monoclonal antibodies provided with the Immunotech Gliadin ELISA kit. As internal calibrators, 0 and $9 \mathrm{ng}$ gliadin solutions were added to separate wells. Wells with the different mixes were incubated for another hour at RT. Afterwards bound gliadins were quantified using a polyclonal antibody (horseradish peroxidase conjugate) that binds to the solid phase antibody-antigen complex. Bound secondary antibody was quantified using TMB substrate (tetramethylbenzidine) as described in the kit. Positive signals were given as absorbance units at $450 \mathrm{~nm}$.
Concentration dependency of peptide gliadin-anti-gliadin antibody binding inhibition

Gliadin was diluted to a final concentration of $1 \mathrm{ng} / \mathrm{ml}$ in $200 \mu \mathrm{l} 0.1 \mathrm{M} \mathrm{NaHCO}_{3}$ dilution buffer as described and mixed with 1.67 nmoles, 0.167 pmoles, and 0.0167 fmoles $\left(10^{15}, 10^{9}, 10^{5}\right.$ molecules) respectively of the biotin-labelled synthetic peptides P61, P64, and CP31, dissolved in $0.1 \mathrm{M} \mathrm{NaHCO}_{3}$ buffer. After incubation for 1 $h$ at RT the gliadin/peptide mixtures were then added to the anti-gliadin antibody coated microtiter wells and incubated for another hour. Secondary antibody was thereafter added and quantified as absorbance units at $450 \mathrm{~nm}$ as described above.

\section{Dot blot assay}

$4 \mu \mathrm{l}$ of serial dilutions of gliadin proteins in $0.1 \mathrm{M}$ $\mathrm{NaHCO}_{3}$ ( $\mathrm{pH}$ 8.6) were spotted onto $0.45 \mu \mathrm{m}$ nitrocellulose membranes, air dried, and subsequently quenched by soaking into $5 \%$ non-fat milk in PBS overnight at $4{ }^{\circ} \mathrm{C}$. Blocking solution was removed by washing the membranes with PBST $\left(137.9 \mathrm{mM} \mathrm{NaCl}, 1.47 \mathrm{mM} \mathrm{KH}_{2} \mathrm{PO}_{4}\right.$, $8.1 \mathrm{mM} \mathrm{Na}{ }_{2} \mathrm{HPO}_{4}, 2.68 \mathrm{mM} \mathrm{KCl}, 0.05 \%$ Tween-20, $\mathrm{pH}$ 7.4). Biotinylated blocking peptides were diluted in PBS and incubated with the membranes for $3 \mathrm{~h}$ at RT with gentle shaking. After subsequent washing with PBST (four times), anti-biotin AP-linked antibody (diluted 1:3000 with dilute buffer, $50 \mathrm{mM}$ PBS, $\mathrm{pH} 7.2,0.05 \%$ Tween-20) was incubated with the membranes for $2 \mathrm{~h}$ with gentle shaking. Finally, the membranes were washed four times with PBST-0.05\%, once with PBS and the APsubstrate was added. The images were developed with immune-star ${ }^{\mathrm{TM}}$ AP chemiluminescent protein detection system (Bio-Rad Laboratories, Sundbyberg, Sweden).

\section{Western blot analysis}

Gliadin proteins were separated during SDS-PAGE on $12 \%$ Tris-glycine gels. The separated proteins were transferred in transfer buffer $(48 \mathrm{mM}$ Tris, $38.6 \mathrm{mM}$ glycine, $1.6 \mathrm{mM}$ SDS, 20\% methanol) to nitrocellulose membranes (Amersham/Biosciences, Sweden) for $2.5 \mathrm{~h}$ at $90 \mathrm{~mA}$ in a semi-dry electroblotting unit (Z34050-2, Sigma, Stockholm, Sweden). After the protein transfer the membranes were washed with washing buffer (PBS, 0.05\% Tween-20) and blocked with 3\% BSA in PBS overnight at $4{ }^{\circ} \mathrm{C}$. For development of the biotin signal, the same protocol as in the Dot blot assay was used.

The study was approved by the Human Research Ethics Committee of the Medical Faculty, Gothenburg University, Gothenburg, Sweden with the permission number 144-06. The serum samples were obtained from a biobank at the immunological laboratory, Sahlgrenska University hospital, Gothenburg. Biobank samples were selected for high titers of gliadin-specific IgA antibodies and for positive or high titers of anti-tTG antibodies. 
According to the Swedish biobank law, the serum samples were completely impersonalized, which means that the samples cannot be linked to any patient, his or her personal data, or to the clinical evaluation.

\section{Acknowledgements \\ This work was supported by a grant from the Swedish Council for Environment, Agricultural Sciences and Spatial Planning no: 222-2004-2705 given to ASS. We also thank Bruce Downie, University of Kentucky and Britt Gabrielsson from Chalmers University of Technology for critical reading of the manuscript.}

\section{Author details}

'Department of Cell and Molecular Biology, University of Gothenburg, SE40530, Gothenburg, Sweden. ${ }^{2}$ Department of Chemical and Biological Engineering/Food Science, Chalmers University of Technology, SE-41296, Gothenburg, Sweden. ${ }^{3}$ Department of Clinical Bacteriology, University of Gothenburg, SE-40530, Gothenburg, Sweden. ${ }^{4}$ Department of Plant and Environmental Sciences, University of Gothenburg, SE-40530, Gothenburg, Sweden. ${ }^{5}$ Microbiology Institute, Guangxi Academy of Agricultural Sciences, Nanning, Guangxi 530007, PR China.

\section{Authors' contributions}

TC developed and optimised the phage display technology and performed most of the experiments to test the peptides. $\mathrm{KH}$ participated in the gluten purification and gave suggestions during method development. SÖ provided the human antibodies and helped with ELISA experiments. OO and ASS planned the project. OO supervised the work and wrote the manuscript together with TC and KH. All authors read and approved the final manuscript.

Received: 20 August 2010 Accepted: 17 February 2011 Published: 17 February 2011

\section{References}

1. Sollid LM, Markussen G, Ek J, Gjerde H, Vartdal F, Thorsby E: Evidence of a primary association of celiac disease to a particular HLA-DQ alpha/beta heterodimer. J Exp Med 1989, 169:345-350.

2. Sollid LM: Molecular basis of celiac disease. Ann Rev Immunol 2000, 18:53-81.

3. Fasano A, Catassi C: Current approaches to diagnosis and treatment of celiac disease: an evolving spectrum. Gastroenterology 2001, 120:636-651.

4. Hadjivassiliou M, Gibson A, Davies-Jones GA, Lobo AJ, Stephenson TJ, Milford-Ward A: Does cryptic gluten sensitivity play a part in neurological illness? Lancet 1996, 347:369-371.

5. Maki M, Collin P: Coeliac disease. Lancet 1997, 349:1755-1759.

6. Robins G, Howdle PD: Advances in celiac disease. Curr Opin Gastroenterol 2004, 20:95-103.

7. Dube C, Rostom A, Sy R, Cranney A, Saloojee N, Garritty C, Sampson M, Zhang L, Yazdi F, Mamaladze V, et al: The prevalence of celiac disease in average-risk and at-risk Western European populations: A systematic review. Gastroenterology 2005, 128(4 SUPPL 1).

8. Fasano A, Berti I, Gerarduzzi T, Not T, Colletti RB, Drago S, Elitsur Y, Green PHR, Guandalini S, Hill ID, et al: Prevalence of Celiac disease in atrisk and not-at-risk groups in the United States: A large multicenter study. Arch Intern Med 2003, 163:286-292.

9. Lohi S, Mustalahti K, Kaukinen K, Laurila K, Collin P, Rissanen H, Lohi O, Bravi E, Gasparin M, Reunanen A, et al: Increasing prevalence of coeliac disease over time. Aliment Pharmacol Ther 2007, 26:1217-1225.

10. Rubio-Tapia A, Kyle RA, Kaplan EL, Johnson DR, Page W, Erdtmann F, Brantner TL, Kim WR, Phelps TK, Lahr BD, et al: Increased Prevalence and Mortality in Undiagnosed Celiac Disease. Gastroenterology 2009, 137:88-93.

11. Dieterich W, Ehnis T, Bauer M, Donner P, Volta U, Riecken EO, Schuppan D: Identification of tissue transglutaminase as the autoantigen of celiac disease. Nat Med 1997, 3:797-801.

12. Molberg O, McAdam S, Lundin KE, Kristiansen C, Arentz-Hansen H, Kett K, Sollid LM: T cells from celiac disease lesions recognize gliadin epitopes deamidated in situ by endogenous tissue transglutaminase. Eur $J$ Immunol 2001, 31:1317-1323.
13. Nilsen EM, Jahnsen FL, Lundin KEA, Johansen FE, Fausa O, Sollid LM, Jahnsen J, Scott H, Brandtzaeg P: Gluten induces an intestinal cytokine response strongly dominated by interferon gamma in patients with celiac disease. Gastroenterology 1998, 115:551-563.

14. Silano $M$, De Vincenzi M: Bioactive antinutritional peptides derived from cereal prolamins: A Review. Nahrung - Food 1999, 43:175-184.

15. Picarelli A, Maiuri L, Frate A, Greco M, Auricchio S, Londei L: Production of antiendomysial antibodies after in-vitro gliadin challenge of small intestine biopsy samples from patients with coeliac disease. The Lancet 1996, 348:1065-1067.

16. Saalman R, Wold AE, Dahlgren UI, Fallstrom SP, Hanson LA, Ahlstedt S: Antibody-dependent cell-mediated cytotoxicity to gliadin-coated cells with sera from children with coeliac disease. Scand J Immunol 1998, 47:37-42.

17. Arentz-Hansen H, Körner R, Molberg O, Quarsten H, Vader W, Kooy YMC Lundin KEA, Koning F, Roepstorff P, Sollid LM, et al: The intestinal T cell response to alpha-gliadin in adult celiac disease is focused on a single deamidated glutamine targeted by tissue transglutaminase. J Experimen Med 2000, 191:603-612.

18. Shan L, Molberg O, Parrot I, Hausch F, Filiz F, Gray GM, Sollid LM, Khosla C Structural basis for gluten intolerance in celiac sprue. Science 2002, 297:2275-2279.

19. Vader W, Kooy Y, Van Veelen P, De Ru A, Harris D, Benckhuijsen W, Pea S, Mearin L, Drijfhout JW, Koning F: The Gluten response in children with celiac disease is directed toward multiple gliadin and glutenin peptides. Gastroenterology 2002, 122:1729-1737.

20. Sjöström L, Molberg, Körner, Mcadam , Anthonsen, Quarsten, Norén Roepstorff, Thorsby, Sollid : Identification of a Gliadin T-Cell Epitope in Coeliac Disease: General Importance of Gliadin Deamidation for Intestinal T-Cell Recognition. Scand J Immunol 1998, 48:111-115.

21. Meresse B, Chen ZG, Ciszewski C, Tretiakova M, Bhagat G, Krausz TN, Raulet DH, Lanier LL, Groh V, Spies T, et al: Coordinated induction by IL15 of a TCR-independent NKG2D signaling pathway converts CTL into lymphokine-activated killer cells in celiac disease. Immunity 2004, 21:357-366.

22. Hue S, Mention JJ, Monteiro RC, Zhang S, Cellier C, Schmitz J, Verkarre V, Fodil N, Bahram S, Cerf-Bensussan N, et al: A direct role for NKG2D/MICA interaction in villous atrophy during celiac disease. Immunity 2004, 21:367-377.

23. Maiuri L, Ciacci C, Ricciardelli I, Vacca L, Raia V, Auricchio S, Picard J, Osman M, Quaratino S, Londei M: Association between innate response to gliadin and activation of pathogenic T cells in coeliac disease. Lancet 2003, 362:30-37.

24. Tye-Din J, Steward JA, Dromey JA, Beissbarth T, van Heel DA, Tatham A, Henderson K, Mannering SI, Gianfrani C, Jewell D, et al: Comprehensive, quantitative mapping of T cell epitopes in gluten in celiac disease. Sci Transl Med 2010, 2:1-14.

25. Sollid LM, Khosla C: Future therapeutic options for celiac disease. Nat Clin Pract Gastroenterol Hepatol 2005, 2:140-147.

26. Stepniak D, Spaenij-Dekking L, Mitea C, Moester M, de Ru A, Baak-Pablo R, van Veelen $P$, Edens $L$, Koning F: Highly efficient gluten degradation with a newly identified prolyl endoprotease: implications for celiac disease. Am J Physiol Gastrointest Liver Physiol 2006, 291:G621-G629.

27. Gass J, Ehren J, Strohmeier G, Isaacs I, Khosla C: Fermentation, purification, formulation, and pharmacological evaluation of a prolyl endopeptidase from Myxococcus xanthus: Implications for celiac sprue therapy. Biotech Bioeng 2005, 92:674-684.

28. Tye-Din J, Anderson RP, Ffrench RA, Brown GJ, Hodsman P, Siegel M, Botwick W, Shreeniwas R: The effects of ALV003 pre-digestion of gluten on immune response and symptoms in celiac disease in vivo. Clin Immunol 2010, 134:289-295.

29. Alvine Pharmaceutical: A phase 2a, double-blind, placebo controlled study of the efficacy, safety and tolerability of 6-weeks tratment with ALV003 in patients with well-controlled celiac disease. ClinicalTrialsgov [Internet] Bethesda (MD): National Library of Medicine (US); [http:// clinicaltrials.gov/show/NCT00959114], 2000-[cited 2011 Jan 14] NLM Identifier: NTC00004451.

30. Nexpep Pty Ltd: A phase I study to determine safety, tolerability and bioactivity of Nexvax2 in HLA DQ2 ${ }^{+}$volunteers with coeliac disease following a long-term strict gluten-free diet. ClinicalTrialsgov [Internet] Bethesds (MD): National Library of Medicine (US); [http://clinicaltrials.gov/ 
ct2/show/NCT00879749], 2000-[cited 2011 Jan 14], NLM Identifier: NTC00879749.

31. Paterson BM, Lammers KM, Arrieta MC, Fasano A, Meddings JB: The safety, tolerance, pharmacokinetic and pharmacodynamic effects of single doses of AT-1001 in coeliac disease subjects: A proof of concept study. Aliment Pharmacol Ther 2007, 26:757-766.

32. Alba Therapeutics: A phase Illb, randomised, double-blind, placebo controlled, dose ranging, multicenter study to determine the safety, tolerance and efficacy of AT-1001 in celiac disease subjects during a gluten challenge. ClinicalTrials.gov [Internet] Bethesda (MD): National Library of Medicine (US); [http://clinicaltrials.gov/ct2/show/NCT00889473], 2000[2011 Jan 14].

33. De ngelis AM, Rizzello CG, Fasano A, Clemente MG, De Simone C, Silano M, De Vincenzi M, Losito I, Gobbetti M: VSL\#3 probiotic preparation has the capacity to hydrolyze gliadin polypeptides responsible for Celiac Sprue. Biochim Biophys Acta 2006, 1762:80-93.

34. Pinier M, Verdu EF, Nasser-Eddine M, David CS, Vezina A, Rivard N, Leroux JC: Polymeric binders suppress gliadin-induced toxicity in the intestinal epithelium. Gastroenterology 2009, 136:288-298.

35. Smith GP: Filamentous fusion phage: Novel expression vectors that display cloned antigens on the viron surface. Science 1985, 228:1315-1317.

36. Hyde-DeRuyscher R, Page LA, Christiansen DJ, Hyde-DeRuyscher N, Lim A Fredricks ZL, Kranz J, Gallant P, Zhang J, Rocklage SM, et al: Detection of small-molecule enzyme inhibitors with peptides isolated from phagedisplayed combinatorial peptides libraries. Chem Biol 2000, 7:17-25.

37. Meiring MS, Litthauer D, Harsfalvi J, Van Wyk V, Badenhorst PN, Kotze HF: In vitro effect of a thrombin inhibition peptide selected by phage display technology. Thromb Res 2002, 107:365-371.

38. el Tayeb Khallafalla K, Osman AA, Langer M, Mothes T: Affinity peptides for gluten analysis? Proceedings of the 16th Meeting of Working Group of Prolamin Analysis and Toxicity: 2002 Verlag Wissenschaftliche Scripten; 2002, 65-70.

39. Katakura Y, Lim ET, Tsujii S, Omasa T, Suga KI: The importance of ionic strength as a parameter in screening peptide ligands from a phage display library. J Fermentat Bioengineer 1998, 85:447-450.

40. Fennema OR: Food chemistry.Edited by: Inc MD 1996, 447-450.

41. Mimouni B, Robin JM, Azanza JL, Raymond J: Wheat flour proteins: Isolation and functionality of gliadin and HMW-glutenin enriched fractions. J Sci Food Agric 1998, 78:423-428.

42. Shewry PR, (ed.): Wheat gluten protein analysis. St Paul 2003.

43. Wieser $H$, Koehler $P$ : The biochemical basis of celiac disease. Cereal Chem 2008, 85:1-13.

44. Anderson RP, Degano P, Godkin AJ, Jewell DP, Hill AVS: In vivo challenge in celiac disease identifies a single transglutaminase-modified peptides as the dominant A-gliadin T-cell epitope. Nat Med 2000, 6:337-342.

45. Sollid LM: Coeliac disease: dissecting a complex inflammatory disorder. Nat Rev Immunol 2002, 2:647-655.

46. Hoffmann K, Alminger M, Andlid T, Chen T, Olsson O, Sandberg AS: Blocking peptides decrease tissue transglutaminase processing of gliadin in vitro. J Agric Food Chem 2009, 57:10150-10155.

47. Hamer RJ: Coeliac Disease: Background and biochemical aspects. Biotech Adv 2005, 23:401-408.

48. Thompson T: Nutritional Requirements for Gluten-Free Foods. Second International Symposium on Gluten-Free Cereal Products and Beverages Tampere, Finland; 2010, 41-42.

49. See J, Murray JA: Gluten-free diet: The medical and nutritional management of celiac disease. Nutr Clin Pract 2006, 21:1-15.

50. Storsrud S, Malmheden Yman I, Lenner RA: Gluten contamination in oat products and products naturally free from gluten. Eur Food Res Technol 2003, 217:481-485

51. Kumar V, Jain N, Lerner A, Beutner EH, Chorzelski TP, Lebenthal E: Comparative studies of different gliadin in detecting antigliadin antibodies. J Pediatr Gastroenterol Nutr 1986, 5:730-734.

52. Murr C, Ellemunter $H$, Oberhuber G, Hoffmann $Y$, Schmoigl C, Pillwein K: Gliadin IgA antibodies in diagnosis of celiac disease in childhood. Wien Klin Wochenschr 1992, 104:418-422.

53. Eisenmann A, Murr C, Fuchs D, Ledochowski M: Gliadin IgG antibodies and circulating immune complexes. Scand J Gastroenterol 2009, 44:168-171. doi:10.1186/1472-6750-11-16

Cite this article as: Chen et al:: Identification of gliadin-binding peptides by phage display. BMC Biotechnology 2011 11:16.

\section{Submit your next manuscript to BioMed Central and take full advantage of:}

- Convenient online submission

- Thorough peer review

- No space constraints or color figure charges

- Immediate publication on acceptance

- Inclusion in PubMed, CAS, Scopus and Google Scholar

- Research which is freely available for redistribution 